
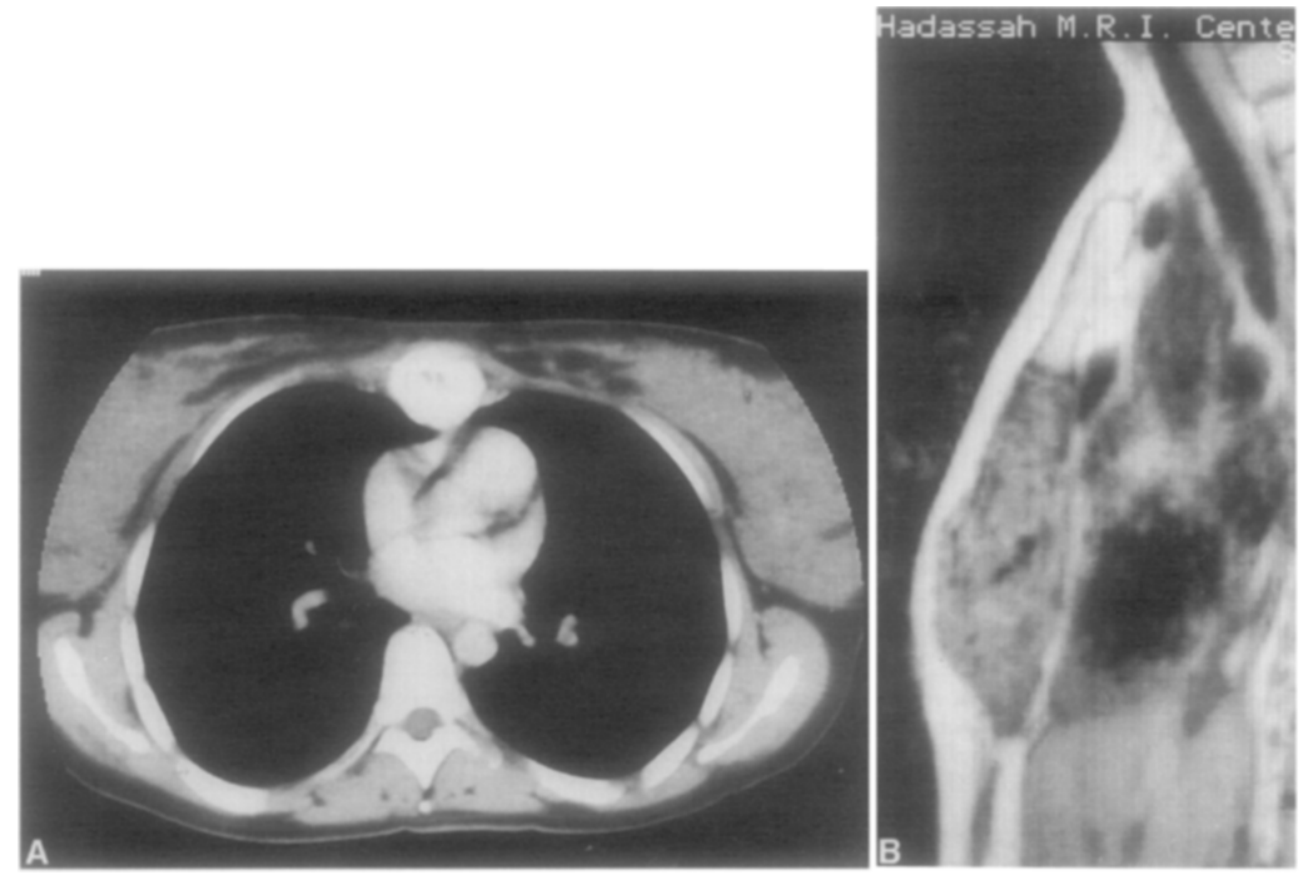

Fig. 1. A, Computed tomographic section of chest showing round mass in body of sternum. B, Longitudinal section of magnetic resonance image of chest showing mass located in lower part of sternal body and invading sternal cortex.

\section{REFERENCES}

1. Sabarantam S, Salama FD, Morgan WE, Harvey JA. Primary chest wall tumors. Ann Thorac Surg 1985;39:4-15.

2. Pascuzzi CA, Dahlin DC, Clagett OT. Primary tumors of the ribs and sternum. Surg Gynecol Obstet 1957;104:390.

3. Ochsner A Jr, Lucas GL, McFarland GB Jr. Tumors of the thoracic skeleton: review of 134 cases. J Thorac Cardiovasc Surg 1966;52:311-21.

4. Boker SM, Cullen GM, Swank M, Just JF. Case report 593: hemangioma of sternum. Skeletal Radiol 1990;19:77-8.
5. Faber LP, Somers J, Templeton AC. Chest wall tumors. Curr Probl Surg 1995;32:661-756.

6. Furst CJ, Lundell M, Holm LE. Radiation therapy of hemangiomas, 1990-1959: a cohort based on 50 years of clinical practice at Radiumhemmet, Stockholm. Acta Oncol 1987;26:33-6.

7. White $\mathrm{CW}$. Treatment of hemangiomatosis with recombinant interferon alfa. Semin Hematol 1990;27:15-22.

8. Trout HH. Management of patients with hemangiomas and arteriovenous malformations. Surg Clin North Am 1986;66: 333-8.

\title{
DIAGNOSTIC USE OF INHALED NITRIC OXIDE AFTER NEONATAL CARDIAC OPERATIONS
}

\author{
Ian Adatia, FRCP(C), Andrew M. Atz, MD, Richard A. Jonas, MD, and David L. Wessel, MD, Boston, Mass.
}

From the Departments of Cardiology and Cardiac Surgery, Children's Hospital, Pediatrics and Surgery, Harvard Medical School, Boston, Mass.

Received for publication April 18, 1996; accepted for publication April 24, 1996.

Address for reprints: Ian Adatia, $\mathrm{FRCP}(\mathrm{C})$, Cardiology and Critical Care Medicine, The Hospital for Sick Children, 555 University Ave., Toronto, M5G 1X8, Canada.

J Thorac Cardiovasc Surg 1996;112:1403-5

Copyright (C) 1996 by Mosby-Year Book, Inc.

$0022-5223 / 96 \$ 5.00+0 \quad \mathbf{1 2 / 5 4 / 7 4 3 3 3}$
The neonatal pulmonary vasculature may be extremely labile. Remodeling of the vessel wall, functional maturation of the endothelial cell, differentiation of the smooth muscle cell, release of vasoactive mediators, and vessel recruitment all contribute to the successful transition to a mature pulmonary circulation. ${ }^{1}$ In the child with pulmonary hypertensive congenital heart disease postnatal remodeling is abnormal. ${ }^{2}$ Even if a neonatal cardiac operation is undertaken, endothelium-dependent pulmonary vascular relaxation may be impaired after cardiopulmonary bypass and the postoperative course may be complicated by transient pulmonary hypertension. $^{3}$ 
Table I

\begin{tabular}{|c|c|c|c|c|c|}
\hline Patient & Sex & Age (days) & Diagnosis & Operation & Response to NO \\
\hline 1 & M & 1 & Obstructed infradiaphragmatic TAPVC & Repair & Yes \\
\hline 2 & F & 1 & Obstructed infradiaphragmatic TAPVC & Repair & Yes \\
\hline 3 & $\mathbf{M}$ & 2 & Obstructed infradiaphragmatic TAPVC & Repair & Yes \\
\hline 4 & $\mathbf{F}$ & 11 & Obstructed infradiaphragmatic TAPVC & Repair & Yes \\
\hline 5 & M & 4 & $\mathrm{D}-\mathrm{TGA} / \mathrm{VSD} / \mathrm{CA}$ & ASO & Yes \\
\hline 6 & M & 5 & IAA/VSD & Repair & Yes \\
\hline 7 & M & 52 & D-TGA/VSD/CA & ASO & No \\
\hline 8 & M & 23 & Truncus arteriosus type IIA & Repair & No \\
\hline 9 & M & 4 & D-TGA & ASO & Yes \\
\hline 10 & M & 30 & D-TGA/VSD/sub-PS & ASO & Yes \\
\hline 11 & $\mathrm{~F}$ & 1 & $\begin{array}{l}\text { Heterotaxy/unbalanced AVC, PA with } \\
\text { obstructed infradiaphragmatic TAPVC }\end{array}$ & $\begin{array}{l}\text { BT shunt } \\
\text { Repair TAPVC }\end{array}$ & No \\
\hline 12 & M & 15 & HLHS & Stage I & Yes \\
\hline 13 & $\mathrm{M}$ & 31 & HLHS & Stage I & No \\
\hline 14 & $\mathrm{~F}$ & 43 & DILV/NRG/aberrant RSCA/sub-AS & Stage I & No \\
\hline 15 & M & 25 & HLHS & Stage I & No \\
\hline
\end{tabular}

NO, Inhaled nitric oxide; $M$, male; $T A P V C$, total anomalous pulmonary venous connection; $F$, female; $D-T G A, D$-transposition of the great arteries; $V S D$, ventricular septal defect; $C A$, coronary artery anomaly; $A S O$, arterial switch operation; $L A A$, interrupted aortic arch; sub-PS, subpulmonary stenosis; $A V C$, atrioventricular canal defect; $P A$, pulmonary atresia; $B T$, modified Blalock-Taussig shunt; $H L H S$, hypoplastic left heart syndrome; stage 1 , stage 1 Norwood operation; $D I L V$, double-inlet left ventricle; $N R G$, normally related great arteries; $R S C A$, right subclavian artery; $S u b-A S$, subaortic stenosis.

Inhaled nitric oxide has been demonstrated to provide safe selective pulmonary vasodilation after cardiac operations. ${ }^{4,5}$ However, pulmonary vasospasm is not the only cause of elevated proximal pulmonary artery pressures. After operation in the neonate with complex congenital heart disease it may be difficult to differentiate between pulmonary vasoconstriction and anatomic obstruction to pulmonary blood flow. A definitive diagnosis may require transport of a sick newborn infant and invasive investigation of the condition.

Therefore we investigated the use of a trial of inhaled nitric oxide after operation in the neonate with pulmonary hypertension or excessive cyanosis to differentiate vasospasm from fixed anatomic obstruction to pulmonary blood flow.

Methods. Fifteen patients with a median age of 11 days (range 1 to 52 days) with pulmonary hypertension (defined as a mean pulmonary artery pressure $>25 \mathrm{~mm} \mathrm{Hg}$ ) or with excessive cyanosis compatible with an elevated pulmonary vascular resistance after cardiac operation underwent challenge with nitric oxide. The characteristics of the patients are summarized in Table I.

All patients were studied after operation while paralyzed and heavily sedated and with the lungs hyperventilated (mean $\mathrm{pH} 7.45 \pm 0.03$, arterial carbon dioxide tension $37 \pm 2 \mathrm{~mm} \mathrm{Hg}$ ). In 10 patients who underwent biventricular repair residual left-to-right shunting was excluded by right atrial and pulmonary artery oximetry and confirmed echocardiographically. Cardiac index was measured by thermodilution in eight patients and by the Fick method with measured oxygen saturation levels and measured oxygen consumption in two. All 10 patients had intraoperatively placed pulmonary artery lines. Hemodynamic variables and oxygen saturation valves were measured at baseline and after a 15-minute inhalation of nitric oxide at a dose of $80 \mathrm{ppm}$. In addition, five patients with excessive hypoxemia after palliation with modified Blalock-Taussig shunts were studied. Systemic arterial oxy- genation was assumed to reflect pulmonary blood flow. Accordingly systemic blood pressure, atrial pressure, and systemic arterial blood gas analysis findings were recorded before and after 15 minutes of nitric oxide inhalation. The details of nitric oxide gas preparation and delivery and monitoring of nitrogen dioxide and methemoglobin levels have been reported. ${ }^{3}$

The Wilcoxon signed rank test was used to compare the change in hemodynamic parameters with nitric oxide. Values are expressed as mean plus or minus standard error.

The study was approved by the investigational review board. Written and informed consent was obtained from the parents.

Results. Nine of 15 patients showed a response with a fall in pulmonary artery pressure or a rise in systemic arterial oxygen saturation after an inhaled nitric oxide challenge. Six patients did not respond and all were found to have anatomic obstruction to pulmonary blood flow.

Eight of 10 patients who had undergone complete neonatal repair showed a response to inhaled nitric oxide with a significant fall in mean pulmonary artery pressure from $35 \pm 4$ to $26 \pm 4 \mathrm{~mm} \mathrm{Hg}(p<0.05)$ and in pulmonary vascular resistance from $17 \pm 6$ to $10 \pm 4 \mathrm{Um}^{2}$ $(p<0.05)$. There was no clinically important change in other hemodynamic parameters. Only one of five patients with single ventricle and severe hypoxemia after initial palliative systemic-to-pulmonary artery shunt procedures responded with an immediate increase in systemic arterial oxygen tension from 19 to $45 \mathrm{~mm} \mathrm{Hg}$. He was treated with continuous low-dose nitric oxide therapy until resolution of pulmonary vasoconstriction occurred.

Two patients (Nos. 7 and 8) with proximal pulmonary artery hypertension (both had undergone right ventricular outflow tract reconstruction) showed no response to inhaled nitric oxide. Further investigation revealed an unobstructed proximal pulmonary anastomosis but hypoplastic branch pulmonary arteries with low distal pulmonary pressures (Fig. 1). Both patients were treated 


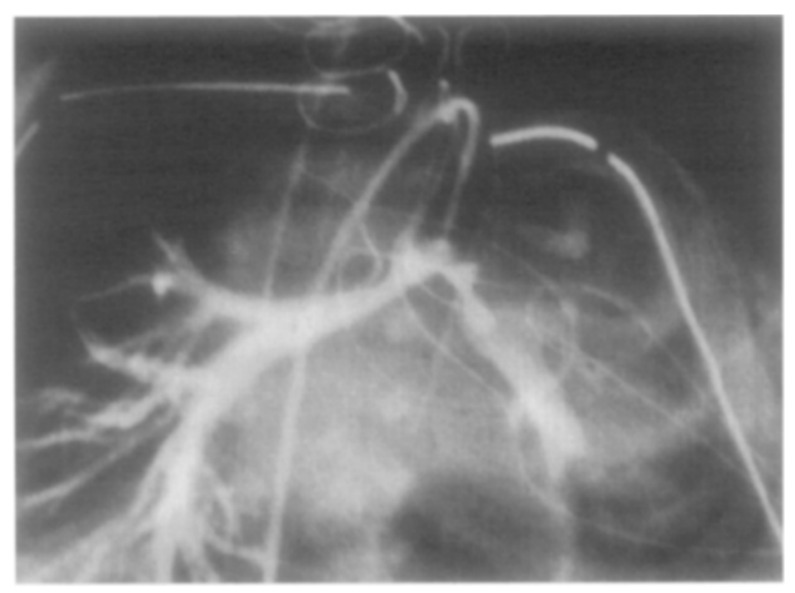

Fig. 1. Angiogram from patient No. 8, who had high proximal pulmonary artery pressures with no response to nitric oxide after repair of truncus arteriosus, demonstrates stenosis at origin of both branch pulmonary arteries distal to anastomosis with homograft. In addition, distal pulmonary arteries are small.

conservatively with subsequent successful balloon dilation of the branch pulmonary arteries. In four of five neonates with refractory cyanosis after receiving modified BlalockTaussig shunts, systemic arterial oxygen saturation did not improve sufficiently $(43 \% \pm 11 \%$ before nitric oxide and $51 \% \pm 8 \%$ with nitric oxide) in response to nitric oxide. All four subsequently were found to have stenotic systemic-to-pulmonary artery shunts. The shunts were revised in all with improvement in oxygenation and three of four have undergone subsequent operation with fenestrated total cavopulmonary anastomoses.

Discussion. In nine newborn patients with elevated pulmonary vascular resistance, inhaled nitric oxide reduced the pulmonary artery pressure and pulmonary vascular resistance selectively without adverse systemic effects, thus confirming pulmonary vasoconstriction as the cause of increased right ventricular afterload. However, in six patients with proximal pulmonary artery hypertension or refractory cyanosis, a postoperative challenge with inhaled nitric oxide failed to reduce pulmonary artery pressure or improve systemic oxygenation. All six patients were found to have anatomic obstruction to pulmonary blood flow. Thus the judicious use of a trial of inhaled nitric oxide may be of value to rule out pulmonary vasoconstriction and direct investigation toward reassessment of the surgical result.

Certain young children with transposition of the great arteries, truncus arteriosus, and single ventricle have labile pulmonary vascular beds with pulmonary vasoconstriction and hypertension. However, high proximal pulmonary artery pressures alternatively may indicate distal pulmonary artery stenosis. In patients with single ventricle, intense cyanosis after insertion of a Blalock-Taussig shunt may reflect systemic-to-pulmonary artery shunt obstruction. We do not propose that a trial of inhaled nitric oxide should replace or delay diagnostic procedures when anatomic obstruction to pulmonary flow is evident. However, in neonatal cases when there is genuine doubt, failure of the patient to show a response to nitric oxide should be regarded as strong evidence of anatomic and possibly surgically remediable obstruction.

We have reported here the use of a short challenge with inhaled nitric oxide after operation in the neonate with congenital heart disease and proximal pulmonary artery hypertension or excessive cyanosis. We have described how the results of such a challenge may be used advantageously to direct therapy in the patient with pulmonary vasoconstriction who shows response to nitric oxide or in the patient who shows no response with further investigation of surgically remediable obstruction to pulmonary blood flow.

\section{REFERENCES}

1. Allen K, Haworth SG. Human postnatal pulmonary arterial remodeling: ultrastructural studies of smooth muscle cell and connective tissue maturation. Lab Invest 1988;59:702-9.

2. Hall SM, Haworth SG. Onset and evolution of pulmonary vascular disease in young children: abnormal postnatal remodeling studied in lung biopsies. J Pathol 1992;166:183-93.

3. Wessel DL, Adatia I, Giglia TM, Thompson JE, Kulik TJ. Use of inhaled nitric oxide and acetylcholine in the evaluation of pulmonary hypertension and endothelial function after cardiopulmonary bypass. Circulation 1993;88:2128-38.

4. Journois D, Pouard P, Mauriat $P$, Malhère T, Vouhé $P$, Safran $D$. Inhaled nitric oxide as a therapy for pulmonary hypertension after operations for congenital heart defects. J Thorac Cardiovasc Surg 1994;107:1129-35.

5. Miller OI, Celermeyer DS, Deanfield JE, Macrae DJ. Very low dose inhaled nitric oxide: a selective pulmonary vasodilator after operations for congenital heart disease. J Thorac Cardiovasc Surg 1994;108:487-94. 